\title{
Health professionals' job satisfaction and associated factors at public health centers in West Ethiopia
}

\author{
Beyazin Kebede Deriba ${ }^{1 *}$, Shimele Ololo Sinke ${ }^{2}$, Berhane Megersa Ereso ${ }^{2}$ and Abebe Sorsa Badacho ${ }^{3}$
}

\begin{abstract}
Background: Human resources are vital for delivering health services, and health systems cannot function effectively without sufficient numbers of skilled, motivated, and well-supported health workers. Job satisfaction of health workers is important for motivation and efficiency, as higher job satisfaction improves both employee performance and patient satisfaction. Even though several studies have addressed job satisfaction among healthcare professionals in different part of the world, there are relatively few studies on healthcare professionals' job satisfaction in Ethiopia.

Methods: A facility-based cross-sectional study was conducted among health professionals working in health centers in April 2015 using self-administered structured questionnaires. All 322 health professionals working in 23 randomly selected public health centers were included. Factor scores were computed for the identified items by varimax rotation to represent satisfaction. Multivariate linear regression analysis was performed, and the effect of independent variables on the regression factor score quantified.
\end{abstract}

Results: Three hundred eight respondents participated with a response rate of $95.56 \%$. The overall level of job satisfaction was $41.46 \%$. Compensation (benefits) (beta 0.448 [95\% Cl 0.341 to 0.554$]$ ), recognition by management (beta 0.132 [95\% Cl 0.035 to 0.228]), and opportunity for development (beta 0.123 [95\% Cl 0.020 to 0.226$]$ ) were associated with job satisfaction. A unit increase in salary and incentives and recognition by management scores resulted in 0.459 (95\% Cl 0.356 to 0.561$)$ and 0.156 (95\% Cl 0.065 to 0.247 ) unit increases in job satisfaction scores, respectively.

Conclusions: The overall level of job satisfaction in health professionals was low. Salary and incentives, recognition by management, developmental opportunities, and patient appreciation were strong predictors of job satisfaction.

Keywords: Health professionals, Job satisfaction, Satisfaction score, Oromia, Ethiopia

\section{Background}

Health services are affected by many factors such as human resources, health delivery, and health infrastructures. Human resources are a vital component for delivering health services, and health systems cannot function effectively without sufficient numbers of skilled, motivated, and supported health workers [1]. Developing capable, motivated, and supported health workers is essential to overcome bottlenecks in achieving national and global health goals. The work force is central to advancing health in every health system [2].

\footnotetext{
* Correspondence: beyaziK@gmail.com

${ }^{1}$ Horro Guduru Zone Health Department, Oromia Health Bureau, Horro, Ethiopia Full list of author information is available at the end of the article
}

There should be an optimal number and professional mix of human resources to deliver effective coverage and quality of the intended services. Despite health and poverty eradication being high on the international agenda, with significant achievements made in some developing countries, progress remains extremely slow in Africa. This is primarily due to weak health systems characterized by severe shortages, poor capacity, and de-motivated health workers at all levels across the continent $[3,4]$.

The presence of high-quality and motivated staff is not only a key aspect of health system performance but also one of the most difficult inputs to ensure [5]. Job satisfaction of health workers is important for motivating employees and improving efficiency, as higher job 
satisfaction is known to improve employee performance and patient satisfaction. Conversely, job dissatisfaction results in burn out, and high employee turnover exacerbates current shortages and results in serious under staffing of healthcare facilities [6].

The definition of job satisfaction varies from person to person and even in the same person from time to time. Job satisfaction generally refers to an evaluation made by the employee of the job and its environment [7]. Job satisfaction can be quantified as the difference between the amount of rewards workers receive and the amount they believe they should receive [8].

Several studies from Africa have shown that job dissatisfaction results from one or more attributes of the work environment such as poor living and working conditions, problems with leadership, inadequate equipment and supplies, lack of recognition for good work, stress due to heavy workloads, and limited opportunities for career development and advancement $[9,10]$.

Ethiopia, as with many other sub-Saharan African countries, also faces shortages in skilled health professionals. This has been accelerated by a variety of factors and has resulted in health worker migration from the public sector, geographical imbalances in workforce staffing, and increasing attrition rates. This health workforce shortage, failures in employing professionals at the right time, retaining them, managing them, and budget shortages with irregular continuing education have critically affected the Ethiopian health system [11].

The loss of clinical staff from low- and middle-income countries (LMICs) is crippling already fragile healthcare systems. Health worker retention is critical for health system performance, and a key problem is how best to motivate and retain health workers [12]. A study conducted on brain drain and retention of health professionals in Africa showed that the continent faces a health crisis due to the very low funding of health services and the deterioration of health service infrastructure. These factors threaten the performance of health workers and job satisfaction [10].

As well as the positive effects of job satisfaction, job dissatisfaction has a negative impact on the organization by decreasing productivity and increasing work accidents, intra-organizational conflict, employee turnover, tardiness, and grievances [13]. Although several reforms and policies have been developed to address health problems in Africa, little attention has been given to health worker job satisfaction and their motivation [14].

In Ethiopia, despite the fact that the government is making substantial programs toward increasing the number, category, and quality of health workers and health infrastructure, service programs still face problems. The national health services tend not to attract health workers since little attention is given to provide incentives, motivation, and adequate remuneration. Thus, effort needs to be made to develop and maintain health worker job satisfaction after identification of significant influencing factors [15].

According to the World Bank 2010 study, health workers tend to be unsatisfied with most aspects of their job in Ethiopia and especially their salary, training opportunities, and chances of promotion. Eighty percent of health professionals are either "unsatisfied" or "very unsatisfied" with their current salary [16].

Although there have been many studies worldwide to address job satisfaction and its factors in health professionals working in hospitals, most previous studies have concentrated on specific profession categories such as nurses, pharmacists, or doctors [13, 17, 18]. Few studies have investigated job satisfaction in different healthcare professionals in Ethiopia, and those that have do not include health center structure. Therefore, this study attempted to address this gap to identify factors influencing job satisfaction among health workers and the extent to which these problems exist in health centers in West Ethiopia.

\section{Methods}

\section{Study area and period}

The study was conducted at selected public health centers in Horro Guduru Wollega, Oromia Regional State, West Ethiopia, from April 1-30, 2015. Horro Guduru Wollega Zone is one of the 18 zones of Oromia Regional State. Shambu, the capital of the zone, is located $314 \mathrm{~km}$ west of Addis Ababa. The total estimated population of the zone is 661790 .

The zone has 10 districts, 9 rural and 1 town administration with 46 health centers and 1 zonal hospital. Five hundred seventy health professionals are employed in the 46 health centers of the zone: 288 nurses, 82 pharmacists, 68 midwives, 32 health officers, 88 laboratory professionals, and 12 environmental health professionals.

\section{Study design}

This was a facility-based cross-sectional study.

\section{Sample size and sampling technique}

Twenty-three health centers were randomly selected from the 46 health centers. All 322 health professionals in these 23 health centers were included in the study.

\section{Data collection tools}

A structured, self-administered questionnaire was used to collect data from participants (Additional file 1). The questionnaire was prepared in English and translated to the local language Afan Oromo and back to English to check for consistency. The study variables were adopted by reviewing relevant literature. 
Data collectors were diploma holders fluent in the local language. The data collectors were given 3-day training on the study objectives, the method of data collection, and the tools for data collection. The data collection tool was pre-tested in another study area.

\section{Data analysis}

Data were entered into EpiData version 3.1 for double verification and exported to SPSS version 20.0 for further analysis. The frequency distribution of all the variables was examined to check for data entry errors. Each study was described using descriptive statistics. Factor analysis was employed for Likert scale instruments to extract factor(s) representing each of the scales and to obtain factor scores. To determine the reliability of the questionnaire, the Cronbach's alpha internal consistency test was used for each dimension. Cronbach's alpha values greater than 0.7 were regarded as acceptable and those $\geq 0.7$ were subjected to factor/principal component analysis (PCA). The Kaiser-Meyer-Olkin test and Bartlett's test were used to assess the appropriateness of using factor analysis and to identify job satisfaction factors.

Factors with eigenvalues greater than one were considered in subsequent analyses. Factor scores were computed for the item identified to represent the satisfaction scale by varimax rotation. Multivariate linear regression analysis was performed, and the effect of independent variables on the regression factor score of the dependent variable quantified. Explanatory variables that had a statistically significant association with the dependent variable $(p<0.05)$ were entered into the final regression model.

\section{Measurement}

Job satisfaction refers to the perception of health professionals about their jobs. It was measured by six items in the satisfaction questionnaire on a 5-point Likert scale from strongly disagree (1) to strongly agree (5) (maximum score 30, minimum score 6). PCA was conducted, and the component score was used as the dependent variable for further analysis. Satisfaction levels were calculated based on the percentage of maximum scale scores. The percentage of maximum scale scores was computed using the formula

Percentage mean score $=($ actual score-potential minimum score $) \times 100 \%$ (potential max. score-potential min. score)

The average of the individual level percentage scale scores and the overall level of satisfaction of the study population were taken [19].

Compensation and benefits refers to health professionals' total pay and was measured by seven items on a 5-point Likert scale from strongly disagree (1) to strongly agree (5). The seven items yielded a maximum score of 35 and a minimum score of 7. PCA was conducted, which produced two meaningful factors with eigenvalues greater than one, which were renamed "salary (incentives)" and "benefit packages." These two factors accounted for about $68 \%$ of the total variance and were used for further analysis.

Recognition and reward refers to acknowledging and rewarding employee performance to encourage effort and was measured by seven items on a 5-point Likert scale from strongly disagree (1) to strongly agree (5) to give a maximum score of 35 and a minimum score of 7 . PCA was conducted to produce two meaningful factors with eigenvalues greater than one, which were renamed "recognition by management" and "patient appreciation." These two factors accounted for about $62 \%$ of the total variance.

Working environment involves the physical, geographical location as well as the immediate surroundings of the work place and infrastructure of the health center including availability of essential materials and supplies. This was measured with eight items on a 5-point Likert scale from strongly disagree (1) to strongly agree (5). PCA was conducted that produced one meaningful factor with an eigenvalue greater than one that accounted for about $50 \%$ of the total variance. The component score was used in further analyses.

Developmental opportunities refers to the perception of the likelihood of being promoted by the health center and was measured by five items on a 5-point Likert scale from strongly disagree (1) to strongly agree (5). These five items yielded a maximum score of 25 and a minimum score of 5 . To examine the underlying factors (components) of the developmental opportunity scale, PCA was conducted, which produced one meaningful factor with an eigenvalue greater than one accounting for about $67 \%$ of the total variance.

Relationship with management refers to the perception of health professionals toward their health center head and management bodies. Twelve items on a 5-point Likert scale were used. All 12 items yielded a maximum score of 60 and a minimum score of 12. PCA was conducted that produced two meaningful factors with eigenvalues greater than one that were renamed "better management" and "good communication." These accounted for about $67 \%$ of the total variance.

Staff working relationship refers to the working relationship within staff and was measured by four items (maximum score 20, minimum score 4). To examine the underlying factors (components) of the staff working relationship scale, PCA was conducted. The factor staff working relationship accounted for about $72 \%$ of the total variance, and the component score was used for further analysis. 


\section{Results}

Socio-demographic characteristics of the respondents Three hundred twenty two survey questionnaires were distributed, of which 320 were returned. From the returned questionnaires, 308 were completed fully to give a response rate of $95.65 \%$.

One hundred ninety three $(62.7 \%)$ respondents were males. The mean age was $27.0( \pm 4.35)$ years with a range of 20 to 45 years. One hundred seventy one $(55.5 \%)$ of the respondents were single, and 246 (79.9\%) were diploma holders. Moreover, 289 (93.8\%) respondents were Oromo by ethnicity, and 192 (62.3\%) were protestant. Two hundred twenty one $(71.8 \%)$ had duration of service less than 5 years in the health centers. Fifty-one percent of the respondents were nurses. Eighty-three (26.9\%) had a monthly income of 1300-1500 Ethiopian birr (65-75 US dollars) (Table 1).

\section{Description of health professionals' general job satisfaction}

Of the 308 respondents, almost half (151, 49\%) agreed or strongly agreed that their job had more advantages than disadvantages. However, over two thirds (216, 70.2\%) of the respondents disagreed or strongly disagreed that their income properly reflected their work. Regarding performance evaluation, the majority of respondents $(104,33.8 \%$ and $97,31.5 \%)$ disagreed or strongly disagreed, respectively.

\section{Level of job satisfaction}

The overall level of health professionals' job satisfaction was $41.46 \%$.

\section{Socio-demographic predictors of health professionals' job satisfaction score}

The relationship between socio-demographic variables and job satisfaction score was quantified. Socio-demographic variables explained only $3.8 \%$ of the variability in job satisfaction score. Accordingly, education status and monthly income were significantly associated with job satisfaction score in bivariate analysis. Respondents who were degree holders had a 0.375 unit greater job satisfaction score than diploma holders (95\% CI, 0.098 to 0.652 ). Similarly, respondents who had a monthly salary of $>1970$ Ethiopian birr (98.5 US dollars) had a 0.320 unit greater job satisfaction score than those with a monthly income of 1301-1500 Ethiopian birr (65-75 US dollars) (95\% CI, 0.008 to 0.633 ).

\section{Job-related factors as predictors of health professionals' job satisfaction score}

Variables related to job satisfaction such as compensation and benefits, recognition and reward, working environment, developmental opportunities, relation
Table 1 Socio-demographic characteristics of health professionals working in Horro Guduru Wollega public health centers in West Ethiopia $(n=308)$

\begin{tabular}{|c|c|c|c|}
\hline Variables & & Number & Percent \\
\hline \multirow[t]{2}{*}{ Sex } & Male & 193 & 62.7 \\
\hline & Female & 115 & 37.3 \\
\hline \multirow[t]{2}{*}{ Age category } & $<30$ years & 260 & 84.4 \\
\hline & $\geq 30$ years & 48 & 15.6 \\
\hline \multirow[t]{2}{*}{ Level of education } & Diploma & 246 & 79.9 \\
\hline & Degree & 62 & 20.1 \\
\hline \multirow[t]{3}{*}{ Marital status } & Single & 171 & 55.5 \\
\hline & Married & 135 & 43.8 \\
\hline & Others & 2 & 0.7 \\
\hline \multirow[t]{4}{*}{ Religion } & Protestant & 192 & 62.3 \\
\hline & Orthodox & 92 & 6.5 \\
\hline & Muslim & 92 & 29.9 \\
\hline & Catholic & 4 & 1.3 \\
\hline \multirow[t]{2}{*}{ Ethnicity } & Oromo & 289 & 93.8 \\
\hline & Amhara & 19 & 6.1 \\
\hline \multirow[t]{6}{*}{ Profession } & Health officer & 18 & 5.8 \\
\hline & Nurse & 157 & 51.0 \\
\hline & Midwife & 40 & 13.0 \\
\hline & Lab & 46 & 14.9 \\
\hline & Pharmacy & 42 & 13.6 \\
\hline & Others & 5 & 1.6 \\
\hline \multirow[t]{3}{*}{ Working experience } & $1-5$ years & 221 & 71.8 \\
\hline & $6-10$ years & 66 & 21.4 \\
\hline & $>10$ years & 21 & 6.8 \\
\hline \multirow[t]{4}{*}{ Monthly income } & $<1300$ & 80 & 26.0 \\
\hline & $1300-1500$ & 83 & 26.9 \\
\hline & $1501-1969$ & 71 & 23.1 \\
\hline & $>1970$ & 74 & 24 \\
\hline
\end{tabular}

with management, and staff working relationship were entered into the model. Accordingly, salary and incentives, benefit packages, recognition by management, patient appreciation, working environment, developmental opportunities, better management, clear communication, and staff working relationship showed statistically significant associations with job satisfaction scores. All of the variables had positive associations with job satisfaction scores. A unit increase in salary and incentives score caused an increment of 0.608 units in job satisfaction score (95\% CI, 0.519 to 0.697 ). Similarly, a unit increase in developmental opportunities and patient appreciation score produced 0.447 (95\% CI, 0.346 to 0.548 ) and 0.365 (95\% CI, 0.260 to 0.470$)$ unit increases in job satisfaction scores, respectively (Table 2 ). 
Table 2 Association of job-related factors and health professionals' job satisfaction score in Horro Guduru Wollega public health centers in West Ethiopia

\begin{tabular}{|c|c|c|c|c|c|c|c|}
\hline \multirow[t]{2}{*}{ Variables } & \multicolumn{2}{|c|}{ Unstandardized coefficient } & \multirow{2}{*}{$\begin{array}{l}\text { Standardized coefficient } \\
\text { Beta }\end{array}$} & \multirow[t]{2}{*}{$T$} & \multirow[t]{2}{*}{$p$ value } & \multicolumn{2}{|c|}{ Confidence interval } \\
\hline & $\overline{\text { Beta }}$ & Std. error & & & & $\overline{L B}$ & UB \\
\hline Enough salary and incentives & 0.608 & 0.045 & 0.608 & 13.392 & 0.000 & 0.519 & 0.697 \\
\hline Benefit package & 0.108 & 0.057 & 0.108 & 1.908 & 0.057 & -0.003 & 0.220 \\
\hline Recognition by management & 0.296 & 0.055 & 0.296 & 5.424 & 0.000 & 0.189 & 0.404 \\
\hline Patient appreciation & 0.365 & 0.053 & 0.365 & 6.860 & 0.000 & 0.260 & 0.470 \\
\hline Working environment & 0.358 & 0.053 & 0.358 & 6.699 & 0.000 & 0.253 & 0.463 \\
\hline Developmental opportunities & 0.447 & 0.051 & 0.447 & 8.744 & 0.000 & 0.346 & 0.548 \\
\hline Better management & 0.319 & 0.054 & 0.319 & 5.889 & 0.000 & 0.212 & 0.426 \\
\hline Clear communication & 0.252 & 0.055 & 0.252 & 5.453 & 0.000 & 0.143 & 0.361 \\
\hline Staff working relationship & 0.271 & 0.055 & 0.271 & 4.934 & 0.000 & 0.163 & 0.380 \\
\hline
\end{tabular}

\section{Predictors of job satisfaction scores}

All of the variables with $p$ values $<0.25$ with health professionals' job satisfaction scores in bivariate linear regression analyses were entered into a multiple regression model. The final model explained about $44.9 \%$ of the variation in job satisfaction score. Salary and incentives, recognition by management, developmental opportunities, and patient appreciation were found to be strong predictors of job satisfaction score. Sufficient salary and incentives had the largest influence on the level of job satisfaction, but none of the demographic characteristics had a significant association with job satisfaction. A unit increase in salary and incentives score and recognition by management score caused 0.459 (95\% CI, 0.356 to 0.561 ) and 0.156 (95\% CI, 0.065 to 0.247 ) unit increases in job satisfaction scores, respectively (Table 3 ).

\section{Discussion}

This study was important to identify the factors that affect health professionals' job satisfaction to focus attention on particular factors and provide possible interventions. Previous studies on health professionals' job satisfaction in Ethiopia have been limited to the hospital setting and specific professions, making them difficult to directly compare with this study [20-22].

The overall level of health professionals' job satisfaction was $41.46 \%$, suggesting that most health professionals are not satisfied with their current job. This result was lower than that found in similar studies conducted in Egypt, Greece, and China, in which the overall level of job satisfaction was $61.24 \%, 74.63 \%$, and $83.3 \%$, respectively. This difference might be because the economic status and working conditions in these countries are better than those in Ethiopia [23-25]. However, this result was higher than a study of nurses in Addis Ababa and Pakistan, with overall levels of job satisfaction of $37 \%$ and $33 \%$, respectively. This might be explained by the work load among nurses in these health facilities [22, 26].

No socio-demographic characteristic was significantly associated with job satisfaction score in the current study, consistent with similar studies conducted in health centers in Turkey and Pakistan [27, 28]. However, in a Malaysian study on human resources employees, gender and marital status did not affect job satisfaction but age, tenure, and education level did [29]. Therefore, previous studies are inconclusive and mixed, perhaps due to differences in culture and the nature of the employees studied.

We report that sufficient salary and incentives, recognition by management, patient appreciation, and developmental opportunities were significant predictors of job satisfaction. Salary (incentives) was the strongest predictor of job satisfaction (beta 0.448 ) followed by recognition by management (beta 0.132). This is

Table 3 Predictors of health professionals' job satisfaction score in Horro Guduru Wollega Zone public health centers in West Ethiopia, April 2015

\begin{tabular}{|c|c|c|c|c|c|c|c|}
\hline \multirow[t]{2}{*}{ Variables } & \multicolumn{2}{|c|}{$\begin{array}{l}\text { Unstandardized } \\
\text { coefficient B }\end{array}$} & \multirow[t]{2}{*}{$\begin{array}{l}\text { Standardized } \\
\text { coefficient B }\end{array}$} & \multirow[t]{2}{*}{$t$} & \multirow[t]{2}{*}{$p$ value } & \multicolumn{2}{|c|}{$95 \% \mathrm{Cl}$ for $\mathrm{B}$} \\
\hline & Beta & Std. error & & & & $\mathrm{LB}$ & UB \\
\hline Enough salary and incentives & 0.459 & 0.052 & 0.459 & 8.783 & 0.000 & 0.356 & 0.561 \\
\hline Recognition by management & 0.156 & 0.046 & 0.156 & 3.363 & 0.001 & 0.065 & 0.222 \\
\hline Patient appreciation & 0.125 & 0.049 & 0.125 & 2.534 & 0.012 & 0.028 & 0.222 \\
\hline Developmental opportunities & 0.123 & 0.052 & 0.123 & 2.348 & 0.020 & 0.020 & 0.226 \\
\hline
\end{tabular}


consistent with studies from Uganda and Nigeria among health professionals, in which all of these variables were predictors of job satisfaction. There is likely to be some commonality in these developing countries since the working conditions and the health systems of these countries are likely to be similar [30, 31].

We also considered compensation (benefits); that is, financial and non-financial benefits from public health centers. Salary (incentives) was significant and entered into the final model. This is in line with a Ugandan study in which salary (incentives) was a significant predictor of the overall level of job satisfaction. Similarly, studies from Turkey and Malaysia also reported that salary was a strong predictor of overall job satisfaction. If an employee is compensated enough according to his needs, he is more likely to manage overload work. According to Herzberg's hygiene theory, salary is a factor that leads employees from dissatisfaction to no dissatisfaction [27, 29, 32].

Recognition by management and patient appreciation were significantly associated with job satisfaction $(p<0.05)$. Recognition of staff can be one of the easiest and most cost-effective strategies to retain experienced health professionals. A study from the Sidama Zone public health facilities indicate that health workers who perceived having more recognition for outstanding performance or achievements reported a higher level of job satisfaction. This result was supported by Herzberg's and Maslow's theories, which identified recognition as a determinant of job satisfaction [21,33].

Developmental opportunities was a dimension that also affected satisfaction, which consists of variables related to training, education, and fairness and chance of promotion. Our results were consistent with similar studies from Pakistan that reported that developmental opportunities was significantly associated with job satisfaction in the context of most respondents being dissatisfied with the professional and development opportunities received during their professional life. South African and Pakistani studies also reported that developmental opportunities was directly and positively related to job satisfaction $[34,35]$.

There was no significant association between job satisfaction and working environment or relationship with management, in contrast to studies from Malaysia. This may be because most health professionals were working at home and the institutional management was different $[28,29,34]$.

\section{Limitation of the study}

Although the participants were assured of confidentiality, there was a possibility that they either over- or underreported their level of satisfaction.

\section{Conclusions}

This study revealed that the level of health professionals' job satisfaction was generally low. There was no significant association between socio-demographic variables and job satisfaction. Among the job-related factors, compensation (benefits), developmental opportunities, and recognition (award) significantly influences the job satisfaction of health professionals. There was no significant association between job satisfaction and staff working relationship, working environment, or relationship with management. Salary and incentives, recognition by management, developmental opportunities, and patient appreciation were strong predictors of health professionals' job satisfaction.

\section{Additional file}

Additional file 1: (SAV $55 \mathrm{~kb}$ )

\section{Acknowledgements}

The authors' sincere gratitude goes to the study participants. The authors also thank Nextgenediting for editorial help as part of their Global Initiative (https://www.nextgenediting.com).

Funding

Nil.

Availability of data and materials

Datasets generated during and/or analyzed during the current study are available from the corresponding author on reasonable request.

\section{Authors' contributions}

$\mathrm{BK}, \mathrm{SO}$, and BM contributed to the conception and design of the study and data analysis. AS analyzed the data and interpreted the findings. BK conducted and supervised the data collection and management. All authors read and approved the final manuscript.

\section{Authors' information}

BK is a Chief Public Health Specialist, Horu Gudura Zone Health Department. AS is a Lecturer, Wolaita Sodo University, College of Health Sciences and Medicine, School of Public Health, P.O. Box 138.

$\mathrm{SO}$ is an Associate Professor, Jimma University, College of Public Health and Medical Sciences, Department of Health Services Management, P.O. Box 378. BM is a Lecturer, Jimma University, College of Public Health and Medical Sciences, Department of Health Monitoring and evaluation, P.O. Box 378.

\section{Competing interests}

The authors declare that they have no competing interests.

\section{Consent for publication}

Not applicable.

Ethics approval and consent to participate

Ethical approval was obtained from the ethical clearance board of Jimma University with reference number RPGC/447/2015, according to standardized principles and procedures in line with the national and $\mathrm{WHO}$ guidelines. The participants were informed about the purpose of the study, and oral consent was obtained from each study participant.

\section{Publisher's Note}

Springer Nature remains neutral with regard to jurisdictional claims in published maps and institutional affiliations. 


\section{Author details}

Horro Guduru Zone Health Department, Oromia Health Bureau, Horro, Ethiopia. ${ }^{2}$ Department of Health Services Management, College of Public Health and Medicine, Jimma University, Po. box 378, Jimma, Ethiopia. ${ }^{3}$ School of Public Health, College of Health Sciences and Medicine, Wolaita Sodo University, Sodo, Ethiopia.

Received: 27 July 2016 Accepted: 3 May 2017

Published online: 30 May 2017

\section{References}

1. AMREF. Report on training needs assessment for health human resource development in Southern Sudan. AMREF Directorate of Learning Systems; 2005. http://www.iss.it/binary/ures/cont/TNA.1160066497.pdf.

2. Gilson L. Community satisfaction with primary health care services: an evaluation undertaken in the Morogoro Region of Tanzania. Soc Sci Med. 1994:6:767-80

3. Gilson L. Developing a tool to measure health worker motivation in district hospitals in Kenya. Hum Resour Health. 2009;7:40-51.

4. Willis-Shattuck M. Motivation and retention of health workers in developing countries: a systematic review. BMC Health Serv. 2008;8:247.

5. Mow dR. Strategies for adapting to high rate of employee turnover. Hum Resour Manag. 1984;23:365-80.

6. WHO. Improving health worker performance: in search of promising practices. Evidence and Information for Policy, Department of Human Resources for Health Geneva; 2006. www.who.int/hrh/resources/improving hw_performance.

7. Smith PC, Kendall LM, Hulin CL. The measurement of satisfaction in work and retirement. USA: Rand McNally; 1975. p. 5-20. ramayah.com/ journalarticlespdf/jobsatisfaction.

8. Robbins SP. Organizational behavior: concepts, controversies, and applications. 9th ed. Englewood Cliffs: Prentice-Hall; 2000. p. 139-43. https:// www.amazon.com/Organizational-Behavior-Concepts-Controve.

9. Huddart J. The health sector human resource crisis in Africa. Washington, DC: SARA Project, AED; USAID; 2003. an issues paper.

10. Diallo K. The role of wages in the migration of health care professionals from developing countries. Hum Resour Health. 2004:2(1):3.

11. $\mathrm{FMOH}$ E. Best practice in health, first national workshops: regional presentations. Addis Ababa. https://www.unicef.org/.../2011_Esaro_ Regional_-_SIA_evaluation_re.

12. Willis-Shattuck M. Motivation and retention of health workers in developing countries: a systematic review. Biomed Central Health Serv Res. 2008;8(247): 1472-6963.

13. Tzeng HM. The influence of nurses' working motivation and job satisfaction on intention to quit: an empirical investigation in Taiwan. Int J Nurs Stud. 2002;39:867-78.

14. Trends and insights 2004. (Available online at http:www.mckesson.ca/ document/trends 2004.pdf). Accessed on 10 Feb 2014

15. Ethiopia Go, Bank. W. Health sector review. 1sth ed. Addis Ababa: Ethiopian social sector studies; 2004

16. Bank. W. Discovering the real world, health workers' career choices and early work experience in Ethiopia. Washington, DC: Africa Human Development Series; 2010. p. 10.

17. Saifuddin A. Job satisfaction among nurses in Aceh Timur District Nanggroe Aceh Darussalam Province Indonesia. J Public Health Dev. 2008;6. www. aihd.mahidol.ac.th/sites/...journal/janapr2008/research17.pdf.

18. Yaseen A. Effect of compensation factors on employee satisfaction — a study of doctor's dissatisfaction in Punjab. Int J Hum Res Stud ISSN. 2013;3. www. macrothink.org/journal/index.php/ijhrs/article/viewFile/.../2820.

19. Feyissa GT. Stigma and discrimination against people living with HIV by health care providers, south west Ethiopia. 2011

20. Yami A. Job satisfaction and its determinants among health workers in Jimma University Specialized Hospital, Southwest Ethiopia. Ethiop J Health Sciences. 2011;21(Special Issue). https://www.ncbi.nlm.nih.gov.

21. Asegid A. Factors influencing job satisfaction and anticipated turnover among nurses in Sidama Zone, South Ethiopia. 2011.

22. Yimam E. Determinants of nurses ${ }^{\prime}$ job satisfaction in governmental hospital of Addis Abeba. 2010

23. Aletras $\mathrm{VH}$. Development and preliminary validation of a questionnaire to measure satisfaction with home care in Greece. BMC Health Serv Res. 2010; 10:189.
24. Walters BL. Job satisfaction and its modeling among township health center employees in rural China. 2010.

25. Kishk NA, Al Juhani AM. Job satisfaction among primary health care nurses in Al-madinah Al-munawwara. Egypt. 2006;81(No.384). https://www.ncbi. nlm.nih.gov/pubmed/17382059.

26. Bahalkani HA. Job satisfaction of nurses working in tertiary level health care setting in Islamabad, Pakistan; 2011. https://www.ncbi.nlm.nih.gov/pubmed/ 23272454.

27. Bodur S. Job satisfaction of healthcare staff employed at health centers in Turkey. Occup Med J. 2002;52(No. 6: 353-355). occmed.oxfordjournals.org/ content/52/6/353.full.pdf.

28. Kumar R. Job satisfaction among public health professionals working in public sector: a cross sectional study from Pakistan. Hum Res Health. 2013. https://human-resources-health.biomedcentral.com/.../1478-4491-11-2.

29. Teoh WM, Kit-Wei TA, Chong SC, Lew-Sian WO. Job satisfaction level among human resource employees: Malaysia's perspective. Afr J Busi Manage. 2011; 6(2):595-607.

30. Health mo, Uganda Ro. Uganda health workforce study: satisfaction and intent to stay among current health workers. Executive Summary. 2007.

31. Ayamolowo SJ. Job satisfaction and working environment of primary health care nurses in Ekiti state, Nigeria. Int J Caring Sci. 2013;6(Issue 3). www. internationaljournalofcaringsciences.org/.../27.\%20Ayamolowo.

32. Mo H. Uganda Health Workforce Study: satisfaction and intent to stay among current health workers USAID-funded capacity project. 2007.

33. Herzberg Fl. One more time: how do you motivate employees? Harv Bus Rev. 2014:65(5):109-20.

34. Ramasodi JM. Factors influencing job satisfaction among healthcare professionals at South Rand Hospital. Master Thesis. University of Limpopo; 2010. www.ayubmed.edu.pk/JAMC/23-3/Bahalkani.

35. Naveed A. A predictor of job satisfaction a study of glass industry of Lahore (Pakistan). Int J Busi Soc Sci. 2011:2(16).

\section{Submit your next manuscript to BioMed Central and we will help you at every step:}

- We accept pre-submission inquiries

- Our selector tool helps you to find the most relevant journal

- We provide round the clock customer support

- Convenient online submission

- Thorough peer review

- Inclusion in PubMed and all major indexing services

- Maximum visibility for your research

Submit your manuscript at www.biomedcentral.com/submit
C) Biomed Central 